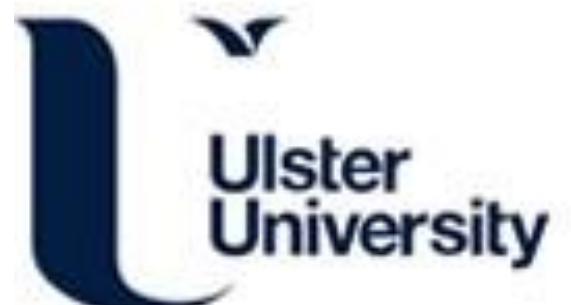

\section{CaV1.3 enhanced store operated calcium promotes resistance to androgen deprivation in prostate cancer}

O'reilly, D., Downing, T., Kouba, S., Potier-cartereau, M., Mckenna, D. J., Vandier, C., \& Buchanan, P. J. (2022).

CaV1.3 enhanced store operated calcium promotes resistance to androgen deprivation in prostate cancer. Cell Calcium, 103, 1-11. [102554]. https://doi.org/10.1016/j.ceca.2022.102554

Link to publication record in Ulster University Research Portal

\section{Published in: \\ Cell Calcium}

Publication Status:

Published (in print/issue): 01/05/2022

DOI:

10.1016/j.ceca.2022.102554

\section{Document Version}

Publisher's PDF, also known as Version of record

\section{General rights}

Copyright for the publications made accessible via Ulster University's Research Portal is retained by the author(s) and / or other copyright owners and it is a condition of accessing these publications that users recognise and abide by the legal requirements associated with these rights.

\section{Take down policy}

The Research Portal is Ulster University's institutional repository that provides access to Ulster's research outputs. Every effort has been made to ensure that content in the Research Portal does not infringe any person's rights, or applicable UK laws. If you discover content in the Research Portal that you believe breaches copyright or violates any law, please contact pure-support@ulster.ac.uk. 


\title{
CaV1.3 enhanced store operated calcium promotes resistance to androgen deprivation in prostate cancer
}

\author{
Debbie O'Reilly $^{1,2,3}$, Tim Downing ${ }^{4}$, Sana Kouba ${ }^{6}$, Marie Potier-Cartereau ${ }^{6}$, Declan \\ J. McKenna ${ }^{5}$, Christophe Vandier ${ }^{6}$, Paul J. Buchanan ${ }^{1,2,3, *}$ \\ ${ }^{1}$ DCU Cancer Research Group, DCU, Ireland \\ ${ }^{2}$ National Institute Cellular Biotechnology, DCU, Ireland \\ ${ }^{3}$ School of Nursing, Psychotherapy and community health, DCU, Ireland \\ ${ }^{4}$ School of Biotechnology, DCU, Ireland \\ ${ }^{5}$ Genomic Medicine Research Group, School of Biomedical Sciences, Ulster University, N.Ireland \\ ${ }^{6}$ N2C UMR 1069, University of Tours, INSERM, Tours, France
}

\section{A R T I C L E I N F O}

\section{Keywords:}

Prostate Cancer

Androgen Deprivation Therapy

CaV1.3

Store operated calcium entry

CACNA1D

Aberrant Intracellular Calcium

Abbreviations

Androgen Deprivation Therapy (ADT)

Androgen Receptor (AR)

Calcium $(\mathrm{Ca} 2+)$

Calcium Channel Blocker (CCB)

Castrate Resistant Prostate Cancer (CRPC)

Cellular Invasion and Migration (CIM)

Colony Formation Assay (CFA)

Cytosolic Calcium (Cac2+)

Glyceraldehyde 3-phosphate dehydrogenase

(GAPDH)

Immunofluorescence (IF)

Intracellular Calcium (Cai2+)

Log2 fold-change (LogFC)

Multiple Comparison Test (MCT)

Principal Components Analysis (PCA)

Prostate Cancer (PCa)

Quality Control (QC)

Thapsigargin $(\mathrm{Tg})$

Tumour Microarrays (TMA)

siRNA CaV1.3 (SiCaV1.3)

SiRNA Control (sictr)

Short Tandem Array (STR)

Store Operated Current (SOC)

\begin{abstract}
A B S T R A C T
Androgen deprivation therapy (ADT) is the main treatment for advanced prostate cancer (PCa) but resistance results in progression to terminal castrate resistant PCa (CRPC), where there is an unmet therapeutic need. Aberrant intracellular calcium $\left(\mathrm{Ca}_{\mathrm{i}}^{2+}\right)$ is known to promote neoplastic transformation and treatment resistance. There is growing evidence that voltage gated calcium channel (VGCC) expression is increased in cancer, particularly CACNA1D/CaV1.3 in CRPC. The aim of this study was to investigate if increased CaV1.3 drives resistance to ADT and determine its associated impact on $\mathrm{Ca}_{\mathrm{i}}{ }^{2+}$ and cancer biology. Bioinformatic analysis revealed that CACNA1D gene expression is increased in ADT treated PCa patients. This was corroborated in both in vivo LNCaP xenograft mouse and in vitro PCa cell line models, which demonstrated a significant increase in CaV1.3 protein expression following ADT with bicalutamide. Expression was found to be of a shortened 170kDa CaV1.3 isoform associated with plasma and intracellular membranes, which failed to induce calcium influx following membrane depolarisation. Instead, under ADT CaV1.3 mediated a rise in basal cytosolic calcium and an increase in store operated calcium entry (SOCE). This mechanism was found to promote the proliferation and survival of ADT resistant CRPC cells. Overall, this study demonstrates for the first time in PCa that under ADT specific CaV1.3 isoforms promote an upregulation of SOCE which contributes to treatment resistance and CRPC biology. Thus, this novel oncochannel represents a target for therapeutic development to improve PCa patient outcomes.
\end{abstract}

Abbreviations: ADT, Androgen Deprivation Therapy; AR, Androgen Receptor; $\mathrm{Ca}^{2+}$, Calcium; CCB, Calcium Channel Blocker; CRPC, Castrate Resistant Prostate

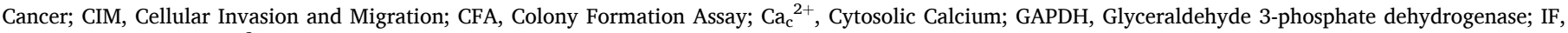

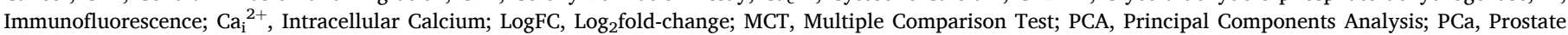

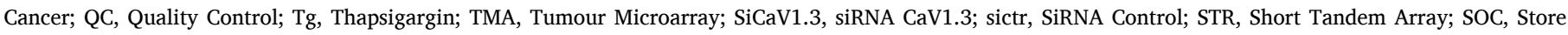
Operated Current; SOCE, Store Operated Calcium Entry; VGCC, Voltage Gated Calcium Channels.

* Corresponding author

E-mail address: paul.buchanan@dcu.ie (P.J. Buchanan). 


\section{Introduction}

Worldwide prostate cancer (PCa) is the most frequently diagnosed malignant tumour in men over sixty years old [1]. Androgen deprivation therapy (ADT) is the main treatment for advance or metastatic disease but associated relapse results in the development of terminal castrate resistant prostate cancer (CRPC) [2]. Further understanding into the mechanisms driving androgen-independent growth is required to highlight new therapeutic targets and improve patient outcomes.

Intracellular calcium $\left(\mathrm{Ca}_{\mathrm{i}}{ }^{2+}\right)$ modulation regulates a number of key cellular processes such as migration, proliferation, apoptosis and expression [3]. Its disruption is known to promote the development of various cancer hallmarks and drive disease progression [4]. The regulation of $\mathrm{Ca}_{\mathrm{i}}{ }^{2+}$ is controlled by a range of calcium channel families, the expression of which are altered across various malignancies [4], including PCa [5,6]. In non-excitable cells, such as that found in cancer, $\mathrm{Ca}_{\mathrm{i}}{ }^{2+}$ is modulated through store operated current (SOC) [7], mediated by release from intracellular stores and associated store operated calcium entry (SOCE) [7]. Research shows that aberrant SOC is linked to various aspects of cancer progression and treatment resistance [8]. $\mathrm{Ca}_{\mathrm{i}}{ }^{2+}$ can also be modulated by membrane potential regulated voltage gated calcium channels (VGCC) [9], but this is normally found in excitable cells. However, microarray meta-analysis of clinical cancer samples has highlighted increases in VGCC gene expression across a range of cancer types [6]. Furthermore, emerging studies show that this family can contribute to aberrant $\mathrm{Ca}_{\mathrm{i}}{ }^{2+}$ and drive cancer biology [4,10,11].

There is growing evidence that gene expression of L-type VGCC, CACNA1D, is upregulated in PCa tissues compared to normal and that it is associated with Gleason score and lymph node status $[6,12]$. In addition, it is a known target of the common somatic alternation present in fifty percent of PCa patients, TMPRSS2:ERG [13]. To date, the single PCa study exploring its protein form, CaV1.3, found it increased $\mathrm{Ca}_{\mathrm{i}}{ }^{2+}$ following androgen stimulation of androgen receptor (AR) positive PCa cell lines [14]. Channel inhibition with calcium channel blockers (CCB), lead to reduced cell proliferation [14]. Similar observations were also made in studies on breast and endometrial cancer cells $[15,16]$. However, CaV1.3's mechanism of action has not been explored in PCa. Traditionally it promotes calcium influx following depolarisation but there is growing evidence of potential non-canonical roles through different channel isoforms [17]. Research previously published by this group in colorectal cancer, demonstrated that CaV1.3 could promote an increase in SOC through interaction with the sodium calcium exchanger [18]. In addition, its outlined role in mediating androgen stimulated $\mathrm{Ca}_{\mathrm{i}}{ }^{2+}$ also suggests an association with SOC, due to its known activation downstream of G-protein coupled receptors such as AR [19]. Interestingly in PCa, ADT is known to contribute to aberrant SOC which in turn supports the development of CRPC [20]. Linked to this, CACNA1D gene and CaV1.3 protein expression has been found to be further increased in CRPC patient samples [12,14]. Despite this the impact of CaV1.3 on $\mathrm{Ca}_{\mathrm{i}}^{2+}$ and associated biology under ADT has not been explored.

Taken together, we hypothesised that the upregulation of CaV1.3 on progression to CRPC drives aberrant SOCE resulting in the development of ADT resistance. This study aimed to explore for the first time the link between $\mathrm{ADT}$ and CaV1.3 expression in a range of in vivo and in vitro models and determine how this affects the channels functional ability to influence $\mathrm{Ca}_{i}{ }^{2+}$ as well as its associated impact on PCa biology. Here we provide evidence of a novel non-canonical role for a short CaV1.3 isoform in mediating SOCE, which is enhanced under ADT driving CRPC biology.

\section{Materials and methods}

\subsection{Cell Culture}

A PCa cell line model of disease progression under ADT was developed using the human AR positive prostate cancer cell line LNCaP (ATCC \# CRL-1740), which represented an androgen sensitive pretreatment control. Two androgen resistant sublines were developed using anti-androgen, $10 \mu \mathrm{M}$ bicalutamide (Sigma). LNCaP-ADT recapitulates early ADT resistance following 10 day ADT, the timepoint associated with significant AR and neuroendocrine gene expression linked to treatment resistance (Figure S1) [21-23]. Additionally, a previously published 2 year ADT insensitive CRPC cell line, LNCaP-ABL, was utilised [24]. All were maintained in RPMI (Gibco) with 10\% fetal bovine serum (Gibco) in a humidified incubator at $37^{\circ} \mathrm{C}$ and $5 \% \mathrm{CO}_{2}$. All cell lines were mycoplasma negative and their origin confirmed via short tandem array (STR) profiling.

\subsection{Prostate xenograft mouse model}

Mice tumour tissue was obtained from previously generated LNCaP xenografted BALB/c immune-compromised (SCID) mice [21]. Tumours were established by subcutaneous injection of LNCaP cells $\left(2 \times 10^{6}\right.$ suspended in $100 \mu$ l of Matrigel) followed by daily treatment administered orally (p.o.) over the course of 21 days with either bicalutamide prepared in vehicle $(0.1 \%$ DMSO in corn oil) or vehicle only. Frozen tissue samples were slowly thawed over ice and sectioned with a sterile blade. As reported in Nesbitt et al [21], bicalutamide treatment significantly reduced tumour growth compared to vehicle only over the 21 days, concomitant with vascular collapse and increased hypoxia in these tumours.

\section{3. $P C R$}

Isolation of cell line RNA was conducted using the High Pure RNA isolation kit (Roche). RNA was isolated from mouse xenograft tumour tissue following homogenisation with a sterile pipette tip in TRIzol reagent (Invitrogen). Total RNA quantified with a nanodrop and purity determined through $\mathrm{A}_{260} / \mathrm{A}_{280}$ ratio. cDNA was synthesised according to instructions for the Transcriptor first strand cDNA synthesis kit (Roche). Lyophilised primers (Sigma Aldrich) were designed using exon spanning sequences in primer3. Gene levels determined using Faststart essential Syber Green master mix (Roche) on a Roche Lightcycler Nano, reaction mix as instructed with $0.5 \mathrm{uM}$ forward and reverse primer and 50ng cDNA. The housekeeping gene HPRT1 was used to calculate relative gene expression with the $-\Delta \Delta$ CT method.

\subsection{Protein preparation}

Total cell lysate was extracted from ice cold cells using RIPA (Thermo Scientific) plus Halt inhibitor cocktail (Thermo Scientific). A cell fractionation kit (Abcam) was used, extracting three fractions, the cytosolic, nuclear and membrane fraction (membrane organelles and the plasma membrane). The included manufactures protocol was followed using approximately $6 \times 10^{6}$ cells for each sample, which were quantified using a Pierce BCA Protein Assay Kit (Thermo Scientific).

\subsection{Western blot}

Electrophoresis was performed using the Mini Gel Tank (Invitrogen) and 4-12\% Bolt Bis-Tris Plus pre-cast gradient gels (Invitrogen). 50ug of 
protein per lane was run and transferred using the Mini Blot module at $20 \mathrm{~V}$ for 60 minutes onto $0.4 \mu \mathrm{m}$ polyvinylidene fluoride (PVDF) in recommended buffers (Invitrogen). Membranes were blocked for one hour at room temperature (RT) in 5\% milk powder TBS-T (Tris buffered saline with tween $20(0.1 \%)$ ). Primary antibody (CaV1.3, Abcam, mouse monoclonal, AB-84811) was used 1:500 in 5\% milk TBS/T overnight at $4{ }^{\circ} \mathrm{C}$. Secondary antibody incubated for one hour at RT in 5\% milk TBS-T at 1:1,000 (HRP-Anti-Mouse, BD Pharmigen, Goat Polycloncal, 554002). Between steps $3 \times 5$ minute washes were performed in TBST. The membrane was incubated with Supersignal West Dura Chemiluminescent Substrate (Thermo Scientific) and exposed to X-ray film before development. Band densitometry conducted using Image $\mathrm{J}$ relative to housekeeping protein Actin (1:10,000, BD Transduction laboratories, Mouse Monoclonal, 612656).

\subsection{SiRNA}

Cells were seeded in plates and grown to $80 \%$ confluency in OptiMEM (Gibco). Dharmacon transfection reagent was used alongside Dharmacon ON-TARGETplus siRNA for Non-targeting (Negative control, sictr) and CACNA1D siRNA (SiCaV1.3). The transfection siRNA mixture was generated with the appropriate volumes in the manufacturer's handbook. Cells where treated with transfection mix in OptiMEM for 48-hours prior to RNA extraction or $\mathrm{Ca}^{2+}$ imaging, or 72hours prior to protein extraction. Percentage knockdown was determined (Figure S2), achieving $>70 \%$ in gene and $>80 \%$ in protein knockdown across all three cell types.

\subsection{Cell proliferation}

Cell proliferation was measured by adding WST-1(Roche, UK) as detailed in manufactures' literature and incubating for 4 hours. Afterwards colorimetric readings at $450 \mathrm{~nm}$ and $690 \mathrm{~nm}$ (Background) were made using the VICTOR multilabel plate reader. The background control was subtracted from each measurement and triplicate average used in the analysis.

\subsection{Colony formation assay (CFA)}

PCa cells seeded at a density of 2500 cells/well and treated 48 hours later. After 14 days of growth the media was aspirated off, cells were washed in PBS before fixing in methanol for 30 minutes followed by staining in 1:10 crystal violet solution for 1 hour. After washing in distilled water, a collection of 50 or more cells was considered a colony and counted.

\subsection{Migration}

The Xcelligence ${ }^{\mathrm{TM}}$ system, Boyden chamber-based assay was used to determine cellular migration. Pre-treated cells were seeded at a density of $8 \times 10^{4}$ cells/well in duplicate in the top chamber of the cell invasion and migration (CIM) plate in $100 \mu \mathrm{l}$ media containing $2 \%$ FBS. The bottom chamber had media containing $10 \%$ FBS as a chemoattractant or $2 \% \mathrm{FBS}$ in the negative control wells. CIM plates were set into the $\mathrm{Xcelligence}^{\mathrm{TM}}$ contained within the incubator at $37^{\circ} \mathrm{C}$ with $5 \% \mathrm{CO}_{2}$. The cell electrical impedance was recorded every 15 mins for 60 hours.

\subsection{Calcium measurements}

To determine relative changes in cytosolic calcium $\left(\mathrm{Ca}_{\mathrm{c}}{ }^{2+}\right)$, PCa cells were suspended in OptiMEM (Gibco) and loaded with $2 \mu \mathrm{M}$ Fura-2-AM ratiometric dye diluted in DMSO in the dark for $45 \mathrm{~min}$. Cells were washed twice in OptiMEM and left for $30 \mathrm{~min}$, before being resuspended in $\mathrm{Ca}^{2+}$ free physiological saline solution (PSS) and seeded into a 96 well black plate. Florescence was measured at $510 \mathrm{nM}$ after excitation at 340 and 380nM using a VICTOR multilabel plate reader. SOC measurements were recorded over time after $5 \mu \mathrm{M}$ Thapsigargin (Tg) induced endoplasmic reticulum depletion followed by application of $2 \mathrm{mM} \mathrm{CaCl}_{2}$ to measure $\mathrm{Ca}^{2+}$ entry (SOCE). Membrane depolarisation was induced by addition of high external potassium solutions of $56 \mathrm{mM} \mathrm{KCl} \mathrm{(K60)} \mathrm{or} 76$ $\mathrm{mM} \mathrm{KCl} \mathrm{(K80),} \mathrm{alongside} \mathrm{osmolality} \mathrm{controls} \mathrm{of} 56 \mathrm{mM} \mathrm{NaCl}$ (Na196) or $76 \mathrm{mM} \mathrm{NaCl}$ (Na216). To ensure CaV1.3 was not already inactivated cells were first hyperpolarised with potassium channel blocker NS1619

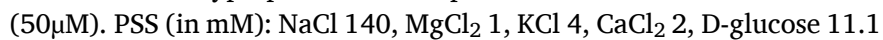
and HEPES 10, adjusted to $\mathrm{pH} 7.4$ with $\mathrm{NaOH}$. The $\mathrm{Ca}^{2+}$ free solution or OCa is a PSS solution without $\mathrm{CaCl}_{2}$ and with $1 \mathrm{mM}$ EGTA. Calcium measurement of peak amplitude of $\mathrm{Tg}$ response and $\mathrm{Ca}^{2+}$ entry was determined by calculating the ratio between baseline and the maximal $\mathrm{Ca}^{2+}$ after application of $\mathrm{Tg}$ or $2 \mathrm{mM} \mathrm{Ca}^{2+}$. The slope for both was determined by linear regression curve fitting $20 \mathrm{sec}$ after treatment to estimate the speed of movement. Area under the curve for total SOC was calculated using Graphpad prism 5 with the trapezoid rule.

\subsection{Prostate cancer patient bioinformatics}

\subsubsection{Data retrieval, quality control and normalisation}

DNA Affymetrix Human Exon 1.0 ST microarray data generated from PCa patient tumour and matched normal radical prostatectomy samples was acquired from previously published Cancer Cell study by Taylor et al [25] (GSE21032). This contained data for 6,553,600 potential probes and was downloaded with $\mathrm{R}$ packages Biobase v2.30.0 and GEOquery v2.40.0. After quality control (QC) there were $n=176$ PCa tumour samples, of which $n=130$ were primary cancers, $n=18$ metastatic tumours and $n=24$ adjacent normal samples (Table S1). 24 of the primary and adjacent samples were paired, allowing comparison of relative expression. Cell line or xenograft samples were excluded. QC and visualisation with principal components analysis (PCA) was implemented with Bioconductor v3.9 to check for outliers based on PCA, which excluded PAN136, PCA040 and PCA208. The data was background-adjusted, quantile-normalised, and log-transformed using the RMA algorithm in affy v3.0 [26] to obtain the samples' normalised expression across 22,011 informative probes.

\subsubsection{Differential expression testing and comparison with patient phenotypes}

Differential gene expression was measured against included pathological and clinical parameters (median 5-year clinical follow-up) of tumour type, hormone treatment, Gleason score and ERG status (Table S1). This was conducted using limma v3.34.4 based on linear models of the $\log _{2}$ fold-change (LogFC) and adjusted p value. Statistical analyses and comparisons with phenotypes were completed with $\mathrm{R}$ packages dplyr v0.7.6, ggplot2 v3.0.0, grid v3.4.1, magrittr v1.5, plyr v1.8.4, readr v1.1.1, survival v2.42.6, tidyr v0.8.1, tidyverse v1.2.1, tidyselect v0.2.4, and xtable v1.8.2. 124. CACNA1D probe (ID 2624385) covered nine mRNA transcripts of both short and long CACNA1D isoforms. Raw $\mathrm{p}$ values were corrected for multiple tests using the Benjamini-Hochberg approach.

\subsection{Statistical analysis}

All graphs were prepared using Prism (Graphpad software, USA). Results are expressed as mean+/-s.e.m unless otherwise stated. Parametric tests were employed when $\mathrm{N}>10$ and included two-tailed unpaired t-test for comparison between two samples, one-way ANOVA with Tukey multiple comparison test (MCT) between $3+$ groups and two-way ANOVA with Tukey MCT for differences between cell types that have been treated with or without siRNA. Non-parametric tests were used for non-normal sample distributions and $N<10$. Nonparametric tests between two groups used a Mann-Whitney test or for multiple groups a Kruskal-Wallis with Dunn's MCT. The statistical tests employed are described in the figure legend, with annotations as ${ }^{*} \mathrm{P}<0.05,{ }^{* *} \mathrm{p}<0.01,{ }^{* * *} \mathrm{p}<0.001$. All results are generated from at least 
three independent experiments denoted by the $\mathrm{N}$ number, with the total number of individual repeats within each denoted by the n number.

\section{Results}

\subsection{Increased CACNA1D expression with PCa progression is associated with $A D T$}

Numerous patient studies highlight that CACNA1D is increased with disease progression to CRPC, a phenotype driven by ADT resistance [6, $12,14]$. We aimed to initially validate the suitability of our microarray dataset by corroborating these observations before further investigating if CACNA1D gene expression was positively correlated with ADT status and other clinical parameters (Table S1). Differential expression testing of existing microarray data [25], showed that CACNA1D expression was significantly increased on average in metastatic compared to primary tumours $(\mathrm{p}=0.035$, Fig. $1 \mathrm{~A})$. Paired primary samples had higher $C A C$ $N A 1 D$ expression than their adjacent normal pairs $(\mathrm{p}=0.018)$. Similarly, the metastatic tumours had increased CACNA1D expression over the adjacent normal samples $\left(\mathrm{p}=1.14 \times 10^{-7}\right)$. As CACNA1D expression was higher in metastatic CRPC, we tested if the development of resistance to
ADT was a driver of the increase in this terminal group. We found that samples (primary and metastatic combined) with ongoing ADT status had significantly higher expression than the ADT untreated samples ( $\mathrm{p}=0.041$ ), as did the pooled ongoing ADT and post-ADT relative to the untreated group ( $\mathrm{p}=0.045$, Fig. 1B). Higher CACNA1D expression was associated with an elevated combined Gleason score in the combined primary and metastatic tumour samples (Fig. 1C). This was supported by observations of higher CACNA1D expression in primary samples with Gleason score 7 relative to $6\left(\mathrm{p}=7.0 \times 10^{-3}\right)$, across Gleason scores 6 to 8 for all samples $(\mathrm{p}=0.012)$ and across the primary ones alone $(\mathrm{p}=0.018)$.

The somatic alteration, TMPRSS2:ERG, is present in about half of all PCa cases resulting in ERG upregulation [13]. CACNA1D is a known ERG target [14,27-30], thus we sought to determine if its expression was associated with ERG status in PCa. Across all samples, those with an ERG-positive status had higher CACNA1D levels than ERG-negative or flat profiles $\left(\mathrm{p}=1.46 \times 10^{-5}\right.$, Fig. 1D). This association held in the primary samples, were ERG-positive samples had higher expression than ERG-negative or flat profiles $\left(\mathrm{p}=1.04 \times 10^{-6}\right)$, but not for metastatic samples, where expression was elevated in both groups (Fig. 1D). Metastatic disease is typically associated with ongoing or post ADT, we
A

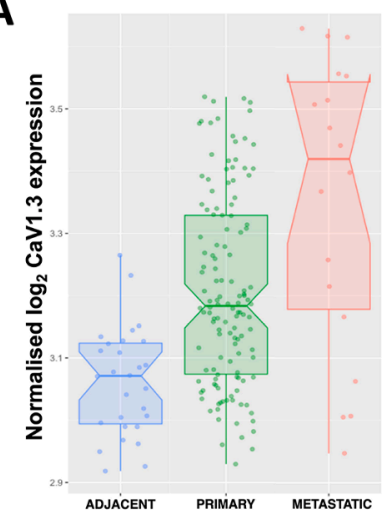

B

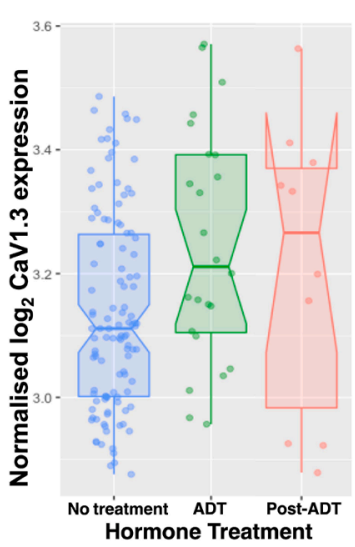

C

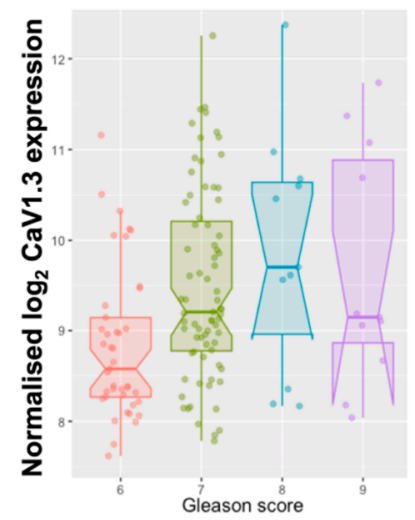

D

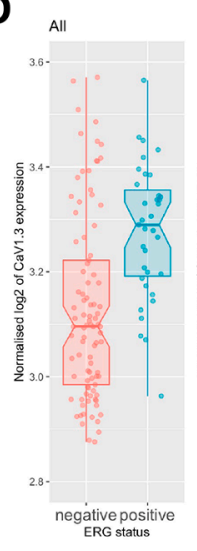

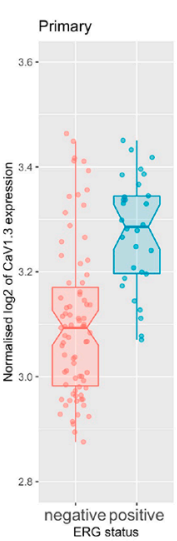

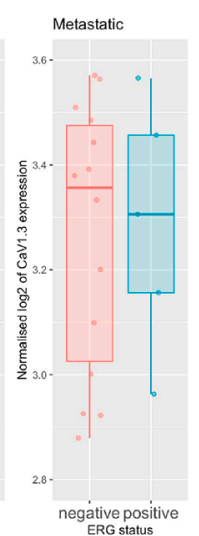

E

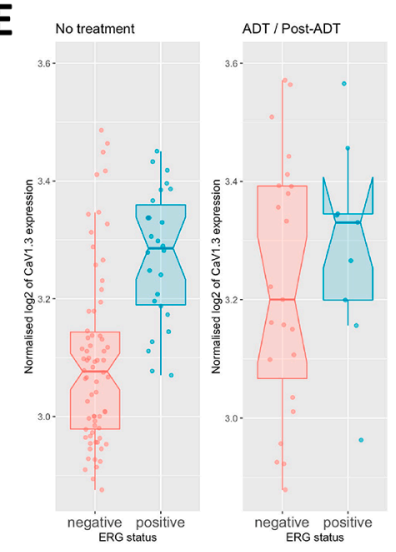

Fig. 1. Prostate cancer patients demonstrate an increase in CACNA1D (CaV1.3) expression associated with sample type, androgen deprivation treatment, ERG status and Gleason score. (A) Normalised CACNA1D (y-axis) expression was $11.3 \%$ higher ( $\mathrm{p}=0.035$ ) in the metastatic (red, $\mathrm{N}=18$ ) than the primary (green, $\mathrm{n}=130$ ) tumours, with $10.3 \%$ and $23.5 \%$ increase in primary and metastatic compared to the adjacent normal samples (blue, $\mathrm{N}=28$ ) (t-test). (B) CACNA1D expression was higher in the post-ADT (red, $\mathrm{N}=10$, median $=3.27$ ) than the ongoing ADT (green, $\mathrm{N}=24$, median=3.21) samples, and both were elevated invidually or pooled $(\mathrm{N}=34)$ compared to the untreated (blue, $\mathrm{N}=114$, median=3.11)(t-test). (C) CACNA1D expression was positively correlated with a higher Combined Gleason score of $6(\mathrm{~N}=73)$ vs $7(\mathrm{~N}=41)$ for the combined primary and metastatic samples (t-test and one-way ANOVA). (D) CACNA1D expression was higher in ERG-positive (red) than $E R G$-negative (blue) tumours in the combined (left panel, $\mathrm{n}=148$ ), the primary (middle panel, $\mathrm{n}=130$ ) but not the metastatic (right panel, $\mathrm{N}=18$ ) samples (ttest). (E) CACNA1D expression (left panel) was higher in the untreated $E R G$-positive (blue, $\mathrm{N}=26$ ) than the untreated $E R G$-negative (red, $\mathrm{N}=70$ ) patients. $C A C N A 1 D$ expression in hormone-treated patients (right panel) was marginally but not statistically higher in $E R G$-positive (blue, $\mathrm{N}=9$ ) than $E R G$-negative (red, $\mathrm{N}=23$ ) patients (t-test). Across all the median values are shown by the horizontal bars, and the notch reflect the interquartile range scaled by the sample size. 
sought to explore further if ADT treatment had an effect on CACNA1D expression independent of ERG regulation (Fig. 1E). Here we observed untreated ERG-positive patients had higher CaV1.3 expression than untreated ERG-negative patients $\left(\mathrm{p}=2 \times 10^{-7}\right)$ (Fig. 1E). In contrast, patients who did receive ADT had elevated CACNA1D expression in both ERG-Negative and ERG-Positive groups (Fig. 1E). Thus, in ERG-negative samples, CaV1.3 expression was elevated in patients receiving hormone therapy compared to those who did not $(\mathrm{p}=0.0106)$.

\subsection{ADT enhances CaV1.3 expression in PCa cell line and mouse models}

To validate that the observed CACNA1D increase in PCa patient samples corresponded to ADT resistance (Fig. 1) we employed a PCa cell line model. This model mimics PCa before and during ADT with a pretreatment androgen sensitive (LNCaP), alongside early androgen deprivation resistance (LNCaP-ADT) and androgen insensitive CRPC (LNCaP-ABL). We found that CACNA1D gene expression was significantly increased in early ADT resistance, LNCaP-ADT $(\mathrm{p}<0.0003)$ and CRPC phenotype, LNCaP-ABL (Fig. 2A). CaV1.3 protein expression in the same model, showed a significant increase in LNCaP-Abl only (p $<0.027$, Fig. 2B).

This link between increased CACNA1D/CaV1.3 expression and ADT resistance was further confirmed using a bicalutamide-treated LNCaP Xenograft mouse model. There were no differences in CACNA1D gene expression across any of the three time points in either bicalutamidetreated or vehicle control samples (Fig. 2C). However, CaV1.3 protein expression increased over time with tumour growth in both vehicle and ADT treated samples $(\mathrm{p}<0.0001)$. It peaked at Day 21 for both ADT $(\mathrm{p}<0.0001)$ and vehicle $(\mathrm{p}=0.0063)$ groups compared to their corresponding day 7 controls (Fig. 2D i+ii), at which point CaV1.3 expression was significantly higher in the ADT group $(\mathrm{p}<0.0092)$ compared to the associated vehicle control (Fig. 2D).

To mediate calcium entry CaV1.3 is typically localised at the plasma membrane as a $250 \mathrm{kDa}$ subunit [9], however in total cell lysates of both cell line and mouse models the molecular weight was $170 \mathrm{kDa}$ (Fig. 2B and $\mathrm{D}$ ). To determine the cellular location and investigate the presence of other CaV1.3 isoforms in the PCa cell line model, protein fractionation was performed. The $170 \mathrm{kDa}$ variant was the most prominently found isoform in the membranous fraction (plasma membrane and intracellular organelles), with increased expression in both ADT treated (LNCaP-ADT and LNCaP-Abl) vs untreated LNCaP. While the expression of the $250 \mathrm{kDa}$ isoform was detected in very low levels in the membranous fraction it was primarily found within the cytosolic fraction. Here it was increased in LNCaP-ADT and further upregulated in LNCaP-Abl both compared to untreated LNCaP control.

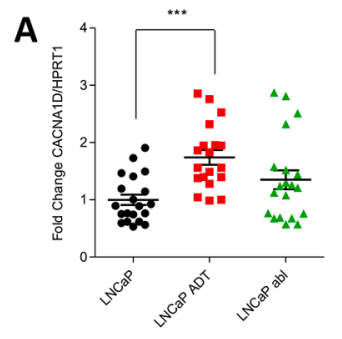

B
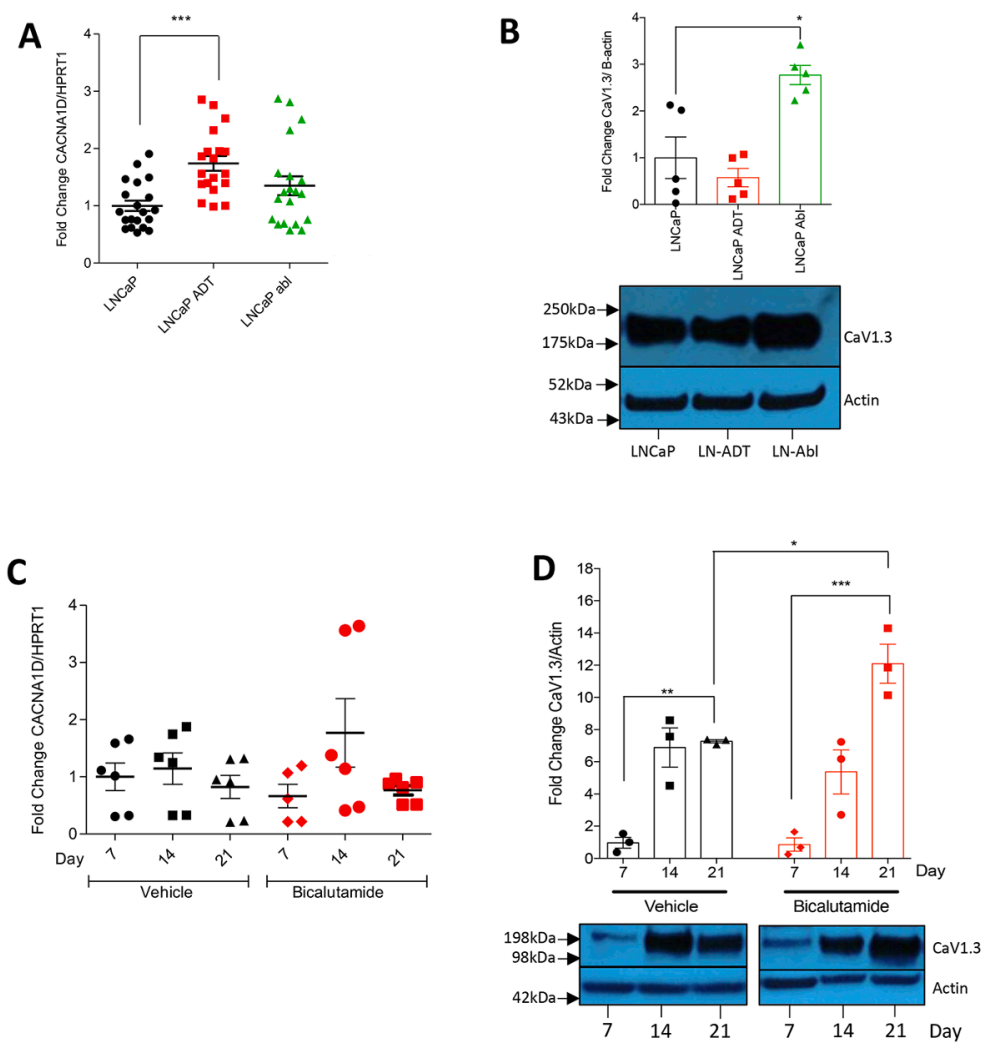
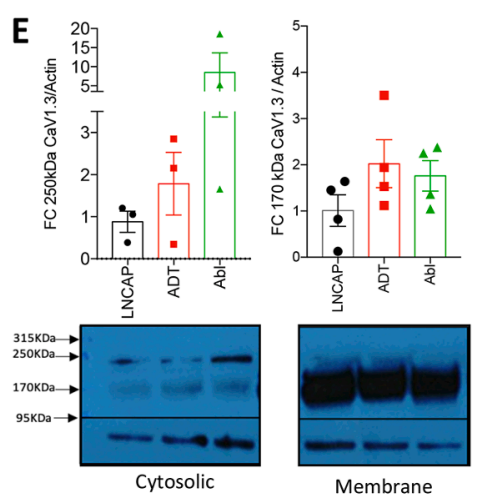

Fig. 2. Expression of CaV1.3 is increased after ADT with bicalutamide in both in vitro PCa cell line and in vivo xenograft mice models. (A) CACNA1D gene expression was measured by qPCR and fold change calculated compared to housekeeping HPRT1 in untreated LNCaP, short term ADT (LNCaP-ADT) or long term ADT (LNCaP-Abl) and normalised to LNCaP ( $\mathrm{N}=10, \mathrm{n}=20$, Kruskal-Wallis-Dunn's MCT). (B) CaV1.3 protein expression in the outlined PCa cell lines was determined by western blot. Fold change was measured by densitometry, normalised to LNCaP and displayed in a bar graph, with a representative blot shown in the lower panel. $(\mathrm{N}=5$, Kruskal-Wallis-Dunn's MCT). (C) Gene expression of CACNA1D was determined in xenografted LNCaP tumours grown in BALB/c mice by qPCR, treated daily with either $10 \mu \mathrm{M} / 2 \mathrm{~kg}$ bicalutamide (Red) or equivalent vehicle control (Black) with samples taken every 7 days up to 21 days. Fold change calculated normalised to corresponding day 7 control and displayed on bar graph. ( $\mathrm{N}=3, \mathrm{n}=6$, Kruskal-Wallis-Dunn's MCT). (D) CaV1.3 expression in outlined PCa mouse model was determined by western blot. Fold change was measured following quantification by densitometry normalised to day 7 vehicle and displayed as a bar chart, with a representative blot displayed below (N=3, two-way ANOVA, Tukey's and Bonferroni's MCT either within or across treatments respectively). (E) Western blot was used to determine CaV1.3 localisation following protein separation into cytosolic $(\mathrm{N}=3)$ and membranous fractions $(\mathrm{N}=4)$ with fold change expression calculated by densitometry with each normalised to untreated LNCaP (Kruskal-Wallis-Dunn's MCT). All PCa cell lines represented as the following, Black circle - LNCaP, Red square - LNCaP-ADT, Green Triangle - LNCaP-Abl. 


\subsection{Increased CaV1.3 under ADT corresponds with increased basal cytosolic calcium}

Owing to the observed upregulation of CaV1.3 under ADT we sought to uncover if this impacted $\mathrm{Ca}_{\mathrm{i}}{ }^{2+}$ compared to untreated, and determine the associated mechanism. As a VGCC, CaV1.3 is expected to promote calcium entry following membrane depolarisation [9]. To investigate if CaV1.3 works through this canonical mechanism in the outlined PCa cell line model $\mathrm{Ca}_{\mathrm{i}}{ }^{2+}$ was measured following the addition of high external potassium to induce membrane depolarisation. Previous research has shown that PCa cell lines have a depolarised membrane potential at rest, thus to ensure CaV1.3 was not already inactivated the cells where first hyperpolarised with potassium channel activator NS1619 [31].

Despite this, no change in $\mathrm{Ca}_{\mathrm{i}}{ }^{2+}$ was observed following the addition of either 56mM (Fig. 3Ai) or $76 \mathrm{mM} \mathrm{KCl} \mathrm{(Fig.} \mathrm{3Bi)} \mathrm{either} \mathrm{with} \mathrm{or} \mathrm{without}$ ADT. Analysis of peak $\mathrm{Ca}_{i}{ }^{2+}$ values under basal or KCL treatment also showed no difference (Fig. $3+$ Bii). High sodium controls (56 and $76 \mathrm{mM}$ ) (Fig. 3A and 3Biii, S3), showed no effect on $\mathrm{Ca}_{\mathrm{i}}{ }^{2+}$ measurements, highlighting that the above result was not influenced by any changes in osmolality due to high external potassium. In addition, basal $\mathrm{Ca}_{\mathrm{i}}{ }^{2+}$ in $2 \mathrm{mM}$ External $\mathrm{Ca}^{2+}$ was measured in the presence of NS1619 (Fig. 3C $\mathrm{i}+\mathrm{ii}$ ) to examine for constitutive calcium entry through the channel, but no significant change was detected across all cell lines either with or without ADT. These experiments suggest that CaV1.3 is not functioning through its traditional voltage gated mechanism. However it has been noted that the channel can play a non-canonical role in SOCE [18]. Measuring in $0 \mathrm{mM}$ external $\mathrm{Ca}^{2+}$ allows us to determine if the channel is implicated in store operated calcium. Interestingly, we found that peak basal $\mathrm{Ca}_{\mathrm{c}}{ }^{2+}$ was increased in ADT treated LNCaP-ADT and LNCaP-Abl
( $<<0.0362$ ) compared to untreated LNCaP (Fig. 3Di+ii). Taking an average of the basal $\mathrm{Ca}_{\mathrm{c}}{ }^{2+}$ traces also demonstrated an increase in LNCaP-ADT $(\mathrm{p}<0.05)$ and LNCaP-Abl $(\mathrm{p}<0.01)$ (Figure S3C).

\subsection{Enhanced SOCE under androgen deprivation conditions is modulated through CaV1.3}

The observed increase in basal $\mathrm{Ca}_{\mathrm{c}}{ }^{2+}$ in $0 \mathrm{mM}$ external $\mathrm{Ca}^{2+}$ and CaV1.3 expression during ADT, suggests that the channel could influence SOCE thus promoting treatment resistance. This hypothesis was supported by fact that compared to other SOC channels such as Orai and STIM, CACNA1D was the most predominately expressed under ADT (Figure S4). To test its role in SOCE, intracellular store release and associated $\mathrm{Ca}^{2+}$ entry was measured either with or without CaV1.3 siRNA knockdown. Validation of siRNA knockdown observed a $70 \%$ and $80 \%$ reduction in both gene and protein levels respectively on average across all three cell lines (Figure S2). Intracellular store release induced by $\mathrm{Tg}$ produced an increase in $\mathrm{Ca}_{\mathrm{c}}{ }^{2+}$ concentration across all three cell lines under non-targeting siRNA conditions compared to basal $\mathrm{Ca}_{\mathrm{c}}{ }^{2+}$ (Fig. 4A, p $<0.0001$, at 275sec). Which was larger in long term ADT LNCaP-Abl ( $<<0.0001$, Fig. 4C) compared to both LNCaP and LNCaP ADT. CaV1.3 siRNA knockdown had no effect on store release in LNCaP, LNCaP-ADT or LNCaP-Abl (Fig. 4B and C). Two-way ANOVA analysis confirmed that $\mathrm{ADT}$ treatment contributed to altered store release $(\mathrm{p}<0.0001)$ but not CaV1.3. Analysis of Tg-induced rising $\mathrm{Ca}^{2+}$ slope demonstrated a similar effect to $\mathrm{Tg}$ peak with a significant increase in LNCaP-ABL compared to both LNCaP and LNCaP-ADT $(\mathrm{p}<0.05$, Fig. 4D), in non-targeting siRNA conditions. Again analysis demonstrated that this effect was due to ADT $(\mathrm{P}<0.0001)$ not CaV1.3.
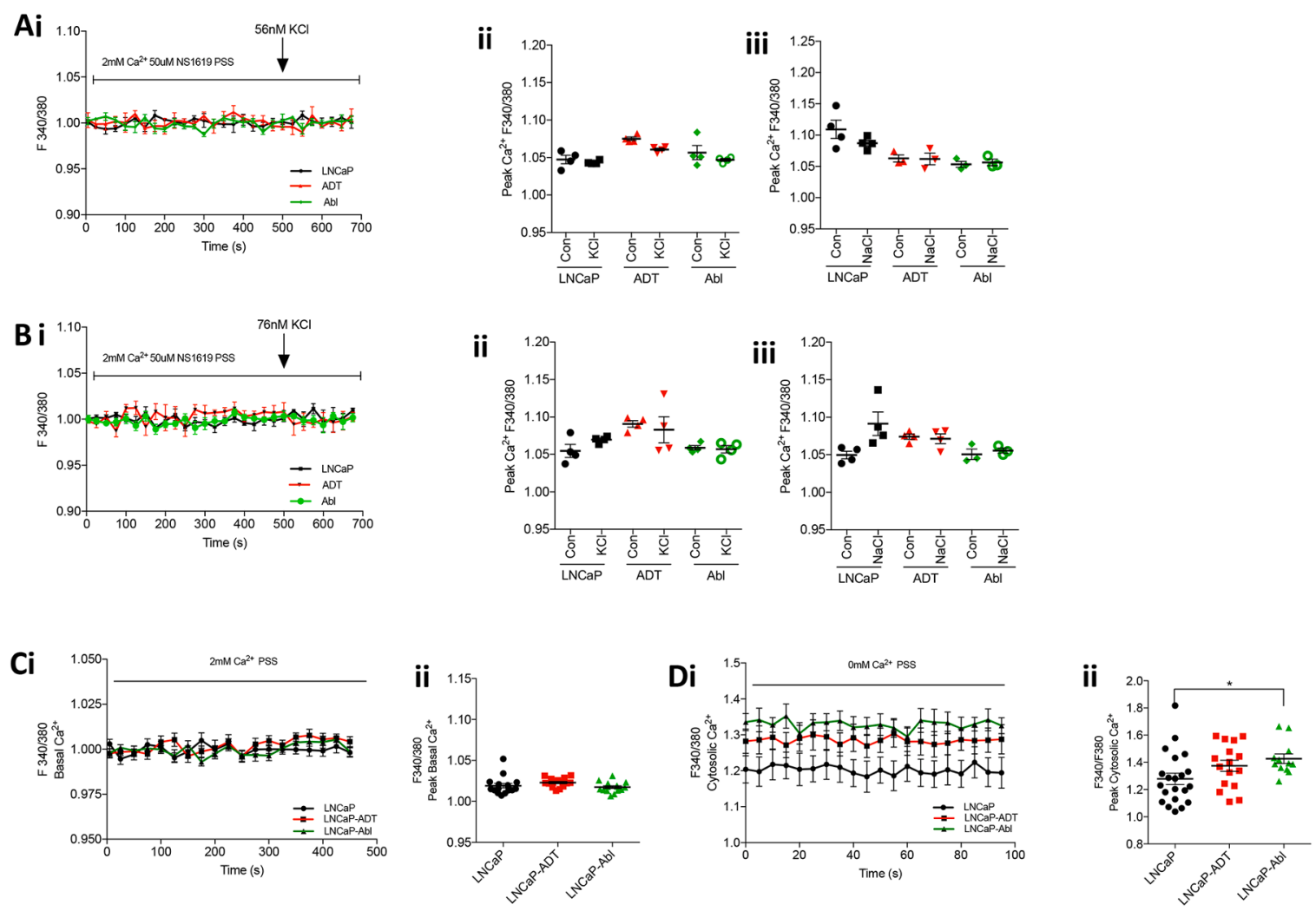

Fig. 3. Increased CaV1.3 under ADT influences basal cytosolic calcium through a non-canonical mechanism. PCa cells were loaded with Fura 2-AM for ratiometeric analysis of calcium $\left(\mathrm{Ca}^{2+}\right)$. Canonical CaV1.3 voltage gated function was tested by depolarisation with addition of high external potassium of (A) $56 \mathrm{nM}$ $\mathrm{KCl}(\mathrm{N}=4)$ or $(\mathrm{B}) 76 \mathrm{nM} \mathrm{KCl}(\mathrm{N}=4)$ in the presence of NS1619 and represented as (i) mean calcium trace over time or (ii) peak fold change after treatment normalised to LNCaP (Kruskal-Wallis-Dunn's MCT). Matched osmolarity controls of (Aiii) $56 \mathrm{mM}$ or (Biii) $76 \mathrm{mM} \mathrm{NaCl}$ displayed as peak fold change after treatment normalised to LNCaP (Kruskal-Wallis-Dunn's MCT). (C) Basal calcium was measured ( $\mathrm{N}=4$ ) in 2mM external $\mathrm{Ca}^{2+}$ including NS1619 for LNCaP ( $\mathrm{n}=16$ ), $\mathrm{LNCaP}-\mathrm{ADT}$ ( $\mathrm{n}=15$ ) or LNCaP-Abl ( $\mathrm{n}=14)$ and (D) Cytosolic calcium $(\mathrm{N}=8)$ was measured in $0 \mathrm{mM}$ external $\mathrm{Ca}^{2+}$ for LNCaP $(\mathrm{n}=22)$, LNCaP-ADT ( $\left.\mathrm{n}=17\right)$ or LNCaP-Abl $(\mathrm{n}=13)$, each are displayed as (i) trace over time or (ii) peak fold change in basal calcium (One-way ANOVA, Dunnett's). 
A

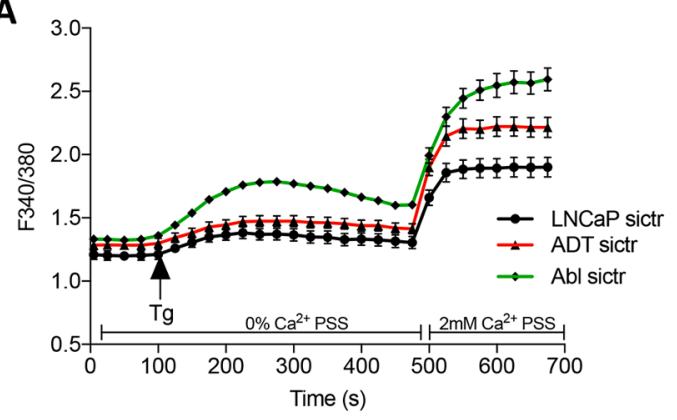

B

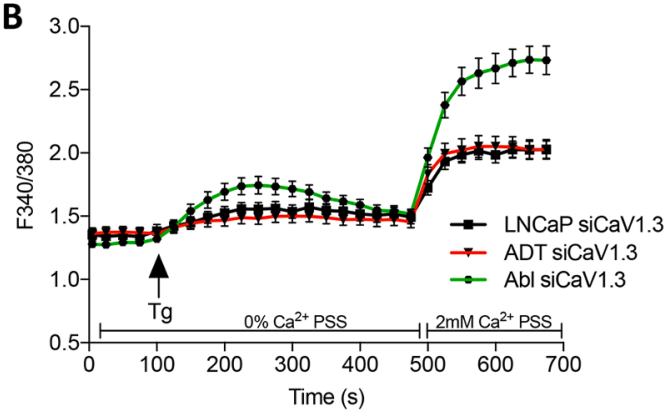

C

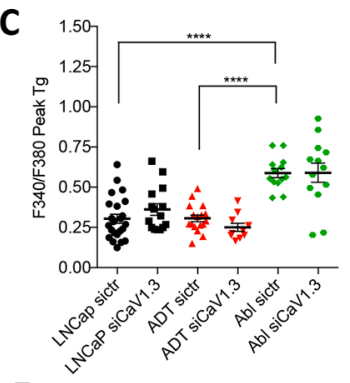

$\mathbf{E}$

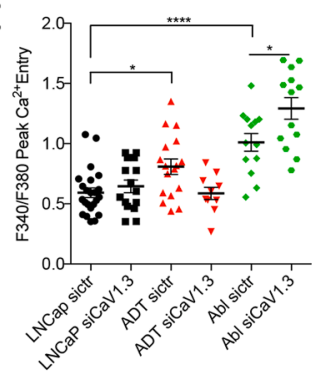

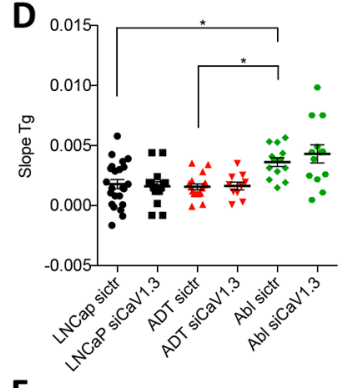

$\mathbf{F}$

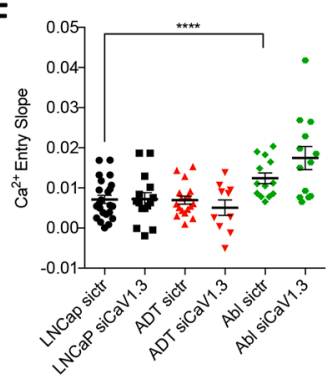

G

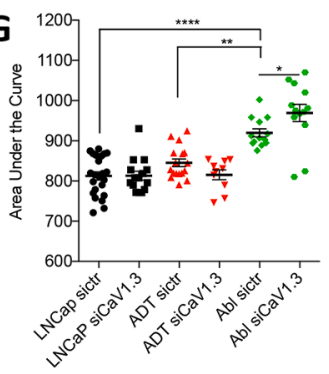

Fig. 4. CaV1.3 drives aberrant SOCE following androgen deprivation. Fura-2AM F340:380 ratiometric $\mathrm{Ca}^{2+}$ traces over time (s) displaying store release induced by Thapsigargin ( $\mathrm{Tg}$ ) in $0 \mathrm{mM} \mathrm{Ca}^{2+}$ followed by store operated calcium entry in the presence of $2 \mathrm{mM}$ extracellular Ca ${ }^{2+}$ under treatment of (A) non-targeting control siRNA (sictr) in LNCaP ( $\mathrm{n}=23)$, LNCAP-ADT( $\mathrm{n}=17)$ and LNCaP-Abl(n=13) or (B) siRNA targeting CaV1.3 (SiCaV1.3) in LNCaP ( $=15)$, LNCAP-ADT(n=10) and LNCaP-Abl(n=13) (Two-way ANOVA, Dunnett's MCT). Dot plots displaying the calculated (C) Tg peak, (D) Tg slope, (E) calcium peak, (F) calcium slope and (G) Area under the curve across each cell type and normalised to LNCaP sictr (Two-way ANOVA, Tukey's MCT and t-test between sictr and sicav1.3).

Following this SOCE was measured by the addition of $2 \mathrm{mM}$ external $\mathrm{Ca}^{2}$, which produced a significant increase in calcium entry under sictr conditions for LNCaP, LNCaP-ADT and LNCaP-Abl (Fig. 4A, all $\mathrm{p}<0.0001)$. It was noted that ADT promoted a significant increase in SOCE in short term treatment (LNCaP-ADT, $\mathrm{p}<0.05$ ), with a further upregulation in long term treatment ( $\mathrm{p}<0.0001$, LNCaP-Abl) compared to untreated LNCaP (Fig. 4E). The role of CaV1.3 in driving this observed increased was measured through CaV1.3 knockdown. In LNCaP cells, not treated with ADT, siCaV1.3 had no impact on SOCE (Fig. 4E). However under short term ADT (LNCaP-ADT) CaV1.3 knockdown completely abolished the rise in $\mathrm{Ca}^{2+}$ entry observed, reducing it to levels witnessed with untreated LNCaP $(\mathrm{P}<0.0242$, Fig. 4E). Interestingly, CaV1.3 knockdown under long term ADT (LNCaP-Abl), increased $\mathrm{Ca}^{2+}$ entry further ( $<<0.05$, Fig. $4 \mathrm{~B}$ and $\mathrm{E}$ ). Analysis of the $\mathrm{Ca}^{2+}$ entry slope found an increase in LNCaP-Abl cells only (Fig. 4F) under sictr and siCaV1.3 (both $\mathrm{p}<0.0001$, Fig. $4 \mathrm{~F}$ ). Total change in SOCE was determined through an area under the curve analysis (Fig. 4G). Mirroring the above results, LNCaP-ADT displayed an increase which was lost under siCaV1.3 ( $\mathrm{p}<0.07)$, to similar levels observed with LNCaP. In LNCaP-Abl an increase was observed compared to untreated LNCaP under siCON $(\mathrm{p}<0.0001)$, which was enhanced further under siCaV1.3 $(\mathrm{p}<0.0001)$ (Fig. 4G). Lastly, we also tested the calcium channel blocker (CCB), nifedipine, on SOCE and found that it had no effect unlike that observed with siCaV1.3 (Figure S5).

\subsection{CaV1.3 mediated increase in SOCE promotes cell proliferation and} survival

Altered $\mathrm{Ca}_{\mathrm{i}}{ }^{2+}$ is known to drive cancer biology, with studies specifically linking CaV1.3 and SOCE to proliferation, survival and migration [8,14-16]. Thus we sought to determine the impact of the observed CaV1.3 mediated SOCE on these aspects of PCa biology under ADT. PCa proliferation was found to be significantly reduced under short term ADT in LNCaP-ADT $(\mathrm{p}<0.0003)$. Whereas proliferation of the long term ADT androgen insensitive LNCaP-Abl cells increased $(\mathrm{p}<0.0001)$ (Fig. 5A). Knockdown of CaV1.3 had no effect on the proliferation of LNCaP or LNCaP-ADT cells but did produce a significant reduction in LNCaP-Abl $(\mathrm{p}<0.0001)$ (Fig. 5Bi-iii). Nifedipine was also tested and found to have no effect on the proliferation of any of the cells (Figure S6). Cell survival measured by colony forming assay (Fig. 5C) was also significantly enhanced in LNCaP-Abl $(\mathrm{p}<0.05)$ compared to untreated LNCaP. CaV1.3 knockdown had no effect on CFA of LNCaP or LNCaP-ADT (Figure Di + ii) but did produce a significant reduction in LNCaP-ABL $(\mathrm{p}<0.029$,Fig. 5Diii). Lastly, metastatic potential was measured by cell index score (Fig. 5Ei), with untreated LNCaP cells demonstrating the highest metastatic potential, which was reduced in LNCaP-ADT and further in LNCaP-Abl $(\mathrm{p}<0.0028)$ (Fig. 5Eii). Under the same conditions CaV1.3 knockdown was observed to have no detectable effect regardless of ADT treatment status.

\section{Discussion}

Multiple studies have demonstrated that the expression of the L-type 

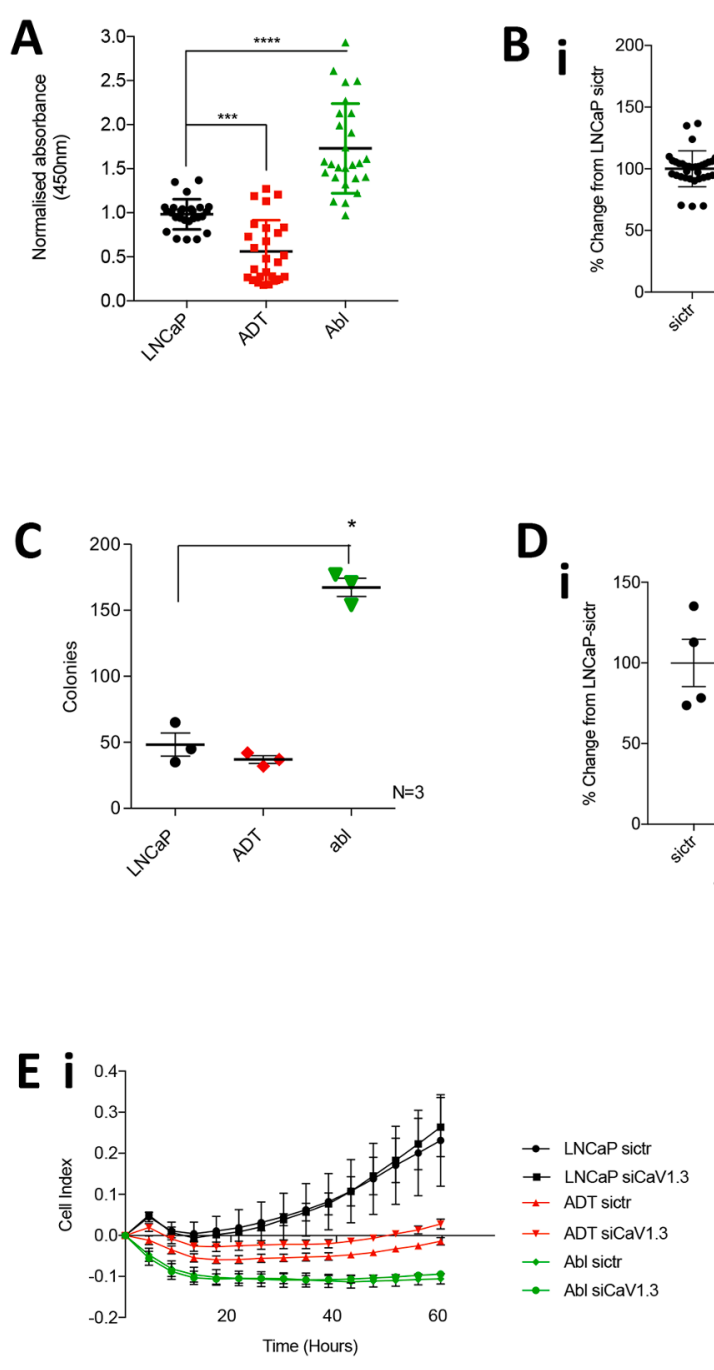

B

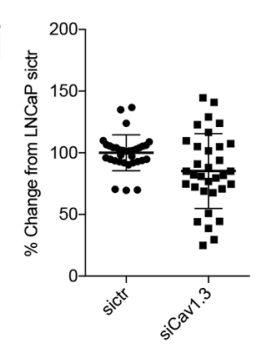

D

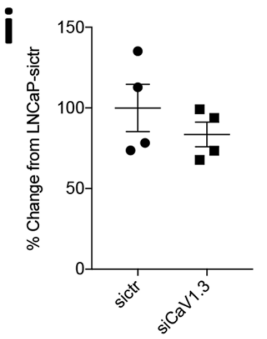

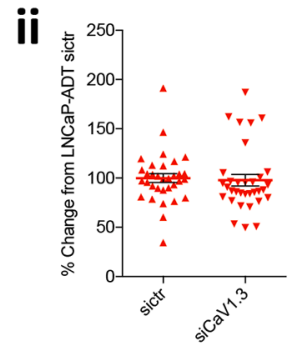

ii

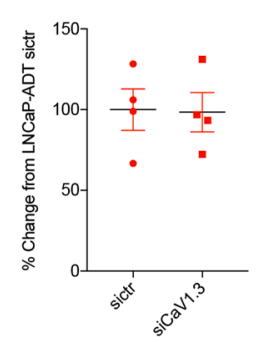

iii

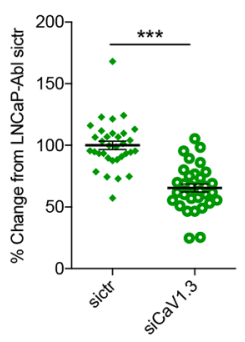

iii

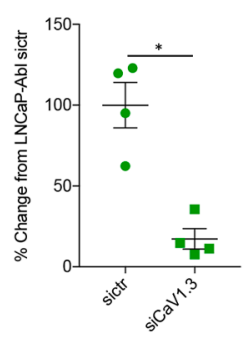

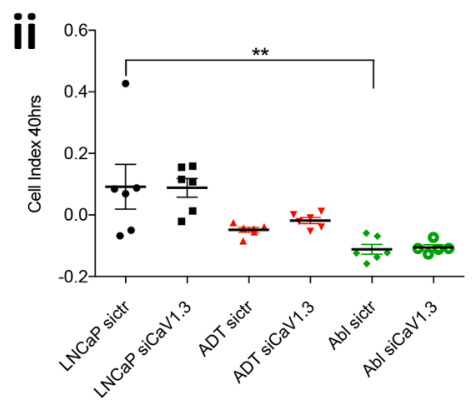

Fig. 5. CaV1.3 mediated aberrant SOCE promotes cell proliferation and survival under long term ADT. Cell proliferation of LNCaP, LNCaP ADT and LNCaP Abl (A) was measured by WST-1 assay with fold change calculated and represented in a dot plot normalised to LNCaP (One-way ANOVA, Tukey MCT, N=9, $\mathrm{n}=26$ ). (B) Fold change in cell proliferation was determined for (i) LNCaP, (ii) LNCaP-ADT, and (iii) LNCaP-Abl, treated with either siRNA control (sictr) or CaV1.3 siRNA (siCaV1.3) (unpaired t-test, $\mathrm{N}=12, \mathrm{n}=33$ ). Cell survival capacity was measured by colony formation assay (C) Total colonies counted between LNCaP, LNCaP ADT or LNCaP-Abl (One-way ANOVA, Tukey MCT, N=3). (D) Fold change in colony count after treatment with sictr or siCaV1.3 for (i) LNCaP, (ii) LNCaP-ADT, and (iii) LNCaP-Abl (Mann-Whitney t-test, $N=4$ ). (Ei) Migration and invasion capacity was measued in CIM plates as cell index over the course of 60 hours in PC cells treated either with sictr or siCaV1.3 ( $\mathrm{N}=6$ ), with (Eii) measurements taken at 40hours for analysis between cells and treatments (Kruskal-Wallis MCT, N=6).

VGCC, CACNA1D/CaV1.3, is positively correlated with progression to CRPC, yet the functional role of this channel and its impact on cancer biology under ADT has remained unknown until now. We sought to investigate these aspects and in particular focus on how the channel contributes to treatment resistance leading to CRPC. Here we demonstrate for the first time that CaV1.3 represents an oncogenic mechanism that drives ADT resistance by promoting aberrant SOCE through a novel non-canonical mechanism, enhancing cell proliferation and survival in CRPC.

Initial bioinformatic evaluation of CACNA1D expression in PCa patient samples noted an upregulation in primary PCa which was further increased in metastatic CRPC, matching similar previous studies $[6,12$, 14]. In addition, this work also supports other studies linking channel expression to increased Gleason score [12,31]. Owing to the fact that ADT resistance promotes CRPC [32], we investigated and found an increase in CACNA1D expression in ADT-treated vs non-treated groups. This has never been shown previously and suggests upregulated $C A C$ NA1D drives ADT resistance. Furthermore, as a known ERG target previous studies have also demonstrated a correlation between $C A C$ NA1D expression and positive TMPRSS2:ERG fusion gene status [14, 27-30,33]. Interestingly, we witnessed this effect in primary PCa only. In metastatic CRPC and ADT treated samples, CACNA1D expression was elevated regardless of ERG status. This novel observation demonstrates that upregulated CACNA1D is not solely linked to TMPRSS2:ERG positive patient cohorts but to any patient with disease progression under ADT. Overall, the associated increase in CACNA1D expression with metastatic disease, Gleason score and ADT highlights its potential as a prognostic tissue biomarker of aggressive disease at risk of progression to CPRC. Indeed, a previous study has found that it holds higher prognostic value than PSA [12]. This potential is further supported by the presence of increased CaV1.3 expression in PCa tissue microarrays produced from routine needle biopsies [14].

To further validate the link between ADT and CaV1.3 expression, LNCaP in vivo xenograft mouse and in vitro cell line models were employed. Both displayed a significant increase in CaV1.3 expression under ADT compared to untreated controls. Studies using this mouse 
model have previously demonstrated that bicalutamide caused vascular collapse and increased hypoxia in these tumours, exerting a selective pressure which favours growth of treatment-resistant cells [21]. In addition, we hypothesize that the observed increase in CaV1.3 expression in the vehicle group, correlating with tumour growth [21], is due to the channels role in supporting proliferation, as well as the presence of hypoxia and associated induction of known survival mechanisms [21]. However, overall the mouse tumour and PCa cell line analysis presented here highlight a link between increased CaV1.3 and ADT resistance, which also corroborates our observations in patient samples. While this is the first study to demonstrate that increased CaV1.3 expression is associated with ADT resistance in PCa, research has shown that expression of other calcium channel families including T-Type VGCC, CaV3.2, can be modulated under similar treatment conditions $[34,35]$.

Going forward the outlined cell line model was used to further investigate the channels' ability to modulate $\mathrm{Ca}_{\mathrm{i}}{ }^{2+}$ under ADT, which to our knowledge has not been studied. While it is well known that cancer cell lines fail to fully represent the heterogenicity of cancer or the tumour microenvironment [36], our initial work validated the suitability of this model by demonstrating changes in CaV1.3 expression under ADT that mimicked our observations in the outlined human and mouse models. In addition, it also provides the ability to investigate changes in cellular electrophysiology and biology that would otherwise be challenging with in vivo models. Our approach of using ADT resistant sublines enabled us to control for genetic differences and discern CaV1.3 mediated changes due to treatment only. The authors acknowledge other known limitations around cell line use such as misidentification, condemnation, genotypic and phenotypic instability [37], which we have mitigated against through myoplasm and genomic testing (Methods 2.1).

As a VGCC, CaV1.3 is known to mediate $\mathrm{Ca}^{2+}$ influx from the plasma membrane upon depolarisation [38]. However, the addition of high external potassium solution failed to induce any changes in $\mathrm{Ca}_{\mathrm{i}}{ }^{2+}$ either with and without ADT. This lack of traditional canonical function can be explained by the fact that the full length $250 \mathrm{kDa}$ isoform, which is known to work through this mechanism [17], was found expressed in the cytosol rather than the plasma membrane. While the shorter $170 \mathrm{kDa}$ isoform was found at the plasma membrane and intracellular stores. Further investigations into $\mathrm{Ca}_{\mathrm{i}}{ }^{2+}$ under ADT in our cell model found an increase in basal $\mathrm{Ca}_{\mathrm{c}}{ }^{2+}$ with both short and long term treatment. This correlated with the observed increase in CaV1.3 expression under ADT (Fig. 2), which was higher than another other SOC channels such as Orai and STIM (Figure S4), suggesting that CaV1.3 was linked to store operated calcium in ADT resistance.

To explore this further we first confirmed the presence of SOCE in our PCa cell line model and found that it increased with ADT and duration of treatment. A number of other studies have also demonstrated the presence of SOCE in a range of PCa cell lines [39-42] including LNCaPs used here in. However, in contrast to our work a decrease in SOCE was observed following ADT [20,39,43]. This variation appears to be related to fact that these studies use shorter treatment time frames and induce androgen deprivation artificially with charcoal stripped media, known to have wide spread cellular effects [44]. In contrast our cellular model used a more clinically relevant treatment with bicalutamide, which specifically blocks androgen signalling only. In addition, this research and others highlight that longer term ADT leads to further changes at the cellular and gene level not found with short term treatment (Figure S1) [45-47].

To assess the impact of increased CaV1.3 on the observed aberrant SOC under ADT an siRNA approach was employed. Interestingly, CaV1.3 knockdown completely abolished the increase in SOCE under short term ADT, while the long-term ADT CRPC LNCaP-Abl cell line observed a further increase in SOCE. This is the first time that CaV1.3 has been shown to influence SOCE in PCa, interestingly it appears that its role changes with treatment time, mediating SOCE directly in early ADT but potentially playing an indirect role reducing SOCE through interaction with other channels. Further research is required to shed light in this area however previous research in other tissues does show coupling of CaV1.3 to intracellular stores through interaction with NCX [18] and also RYR [17,48-50]. In particular it has been suggested that this interaction is isoform specific [17], which would correlate with the presence and upregulation of the shorter $170 \mathrm{kDA}$ CaV1.3 in our cell model. Furthermore, this shorter isoform is known to lack sensitivity to CCB's [17], explaining why the CCB nifedipine failed to impact on SOCE or cell proliferation (Figure $55+6$ ). This important observation potentially accounts for the conflicting epidemiology reports investigating the beneficial effects of CCB use in PCa [51-54]. Alternatively, CaV1.3 has been previously shown to regulate gene transcription through its cleaved $70 \mathrm{kDa}$ c-terminus product $[55,56]$. This study showed the presence of the CaV1.3 c-terminus in the nucleus under short term ADT which was lost under long term treatment and progression to CRPC (Figure S7). This difference could also account for the contrasting effects of CaV1.3 knockdown on SOCE and potentially suggests that the c-terminus could be playing a role influencing the expression of other calcium. Nonetheless further work is required to understand how these isoforms are produced. We suspect through posttranslational proteolytic cleavage of the C-terminus due to the presence of the $250 \mathrm{kDa}$ full length CaV1.3, $170 \mathrm{kDa}$ short form and the 70kDA c-terminal cleavage product, a phenonium that has been previously shown [57]. In addition, as these isoforms appear not to be dependent on specific mRNA transcripts this does not thus impact the microarray gene expression analysis (Fig. 1).

As outlined aberrant SOCE is known to contribute to various cancer hallmarks, promoting treatment resistant and disease progression [8]. Thus the study sought to investigate the impact of CaV1.3 mediated SOCE on PCa biology under ADT. As expected and observed by other studies, short term ADT reduced proliferation, colony formation and migration $[45,47]$. Knockdown of CaV1.3 under these conditions had no effect, suggesting that the channel does not affect these aspects of PCa biology at this stage but further investigations into other cancer hallmarks are required. For example, we show that siCaV1.3 during early ADT does decrease $\mathrm{Ca}_{\mathrm{i}}{ }^{2+}$, a change that has been previously associated with apoptotic resistance [39] and indeed proliferation or survival of LNCaP-ADT is not further decreased by siCaV1.3 while under ADT suggesting this to be the case. Furthermore, LNCaP cells have previously been shown to have little migratory capacity and display a negative cell index [58], which is known to be attributed to loss of adhesion and cell death [59], likely as a result of ADT. Therefore additional work using higher migratory cells is needed to understand the role of CaV1.3 in migration. In contrast, in androgen insensitive CRPC (LNCaP-Abl), cell proliferation and colony formation was increased. This is indicative of progression to an androgen-independent castrate-resistance state as witnessed in patients [60] and shown in PCa cell lines such as LNCaP-Abl [24,61,62]. A number of mechanisms have been proposed to promote this phenotype such as AR alternations [63], however changes in $\mathrm{Ca}_{\mathrm{i}}{ }^{2+}$ such as SOCE have also been linked to PCa progression [40,64, 65]. This suggests that the observed increase in SOCE through CaV1.3 in $\mathrm{LNCaP}-\mathrm{Abl}$ is promoting ADT resistance and contributing to the increase in proliferation and colony formation in CRPC. This decrease in proliferation and CFA after CaV1.3 knockdown in LNCaP-ABL could be explained by the dual role of $\mathrm{Ca}^{2+}$ modulation where a sustained or large increase such as that observed with our SOCE is known to induce apoptosis $[40,66]$. To further confirm the role of CaV1.3 in PCa biology we also knocked down CaV1.3 in androgen resistant PC3 cells, producing a significant decrease in proliferation, also correlation with a reduction in SOCE (Figure S8). Overall, these results highlight the clinical relevance of targeting CaV1.3 in androgen insensitive CRPC, where there is an unmet therapeutic need, instead of a combinational therapy during ADT.

\section{Conclusion}

This novel study demonstrates for the first time that upregulated 
CaV1.3 contributes to ADT resistance by driving aberrant SOCE through a non-canonical mechanism promoting CRPC biology. Bioinformatic analysis uncovered that CACNA1D expression is increased with ADT and progression to metastatic disease, regardless of TMPRSS2:ERG status. This highlights the channel as a potential prognostic tissue biomarker for PCa disease progression under ADT to CRPC. This study also provides new evidence that CaV1.3 function is determined by different isoforms, with the $170 \mathrm{kDa}$ CaV1.3 in PCa modulating SOCE. Moreover, the subsequent increase in CaV1.3 SOCE plays a key role in the development of resistance to ADT enabling PCa biology that contributes to CRPC such as proliferation and survival. Of note, CCB's do not influence $\mathrm{Ca}_{\mathrm{i}}{ }^{2+}$ through this isoform, explaining the conflicting studies investigating the impact of CCB use in PCa. Overall, this research does highlight that targeting different CaV1.3 isoforms could be of therapeutic benefit to later stage ADT resistant disease where there is an unmet need for new treatments. This exciting potential for patient benefit means that further research on CaV1.3 isoforms and associated interacting partners mediating SOCE in $\mathrm{PCa}$ is highly recommended.

\section{Funding}

This project was supported by Dublin City University School of Nursing, Psychotherapy and Community Health PhD studentship [201618]; Irish Research Council (IRC) Government of Ireland Postgraduate Scholarship [GOIPG/2018/373, 2018-21]; and an Ulysses Award [2018] part funded by the IRC and ministères de l'Europe et des affaires étrangères et de l'enseignement supérieur, de la recherche et de l'innovation.

\section{CRediT authorship contribution statement}

Debbie O'Reilly: Methodology, Formal analysis, Writing - original draft, Writing - review \& editing, Visualization. Tim Downing: Methodology, Software, Resources, Data curation, Writing - original draft, Writing - review \& editing. Sana Kouba: Methodology, Resources, Formal analysis, Visualization. Marie Potier-Cartereau: Methodology, Resources. Declan J. McKenna: Methodology, Resources, Writing original draft, Writing - review \& editing. Christophe Vandier: Methodology, Resources, Writing - review \& editing. Paul J. Buchanan: Conceptualization, Methodology, Formal analysis, Resources, Data curation, Writing - original draft, Writing - review \& editing, Visualization, Supervision, Project administration, Funding acquisition.

\section{Conflict of Interest}

The authors have no conflict of interest to declare.

\section{Supplementary materials}

Supplementary material associated with this article can be found, in the online version, at doi:10.1016/j.ceca.2022.102554.

\section{References}

[1] F. Bray, J. Ferlay, I. Soerjomataram, R.L. Siegel, L.A. Torre, A. Jemal, Global cancer statistics 2018: GLOBOCAN estimates of incidence and mortality worldwide for 36 cancers in 185 countries, CA. Cancer J. Clin. 68 (2018) 394-424, https://doi.org/ 10.3322/caac. 21492.

[2] Q. Feng, B. He, Androgen Receptor Signaling in the Development of CastrationResistant Prostate Cancer, Front. Oncol. 9 (2019), https://doi.org/10.3389/ fonc.2019.00858.

[3] M. Prakriya, Calcium and cell function, J. Physiol. 598 (2020) 1647-1648, https:// doi.org/10.1113/JP279541.

[4] S. Tajada, C. Villalobos, Calcium Permeable Channels in Cancer Hallmarks, Front. Pharmacol. (2020) 11, https://doi.org/10.3389/fphar.2020.00968.

[5] N. Prevarskaya, R. Skryma, G. Bidaux, M. Flourakis, Y. Shuba, Ion channels in death and differentiation of prostate cancer cells, Cell Death Differ 14 (2007) 1295-1304, https://doi.org/10.1038/sj.cdd.4402162.
[6] C.-Y. Wang, M.-D. Lai, N.N. Phan, Z. Sun, Y.-C. Lin, Meta-Analysis of Public Microarray Datasets Reveals Voltage-Gated Calcium Gene Signatures in Clinical Cancer Patients, PLoS ONE (2015) 10, https://doi.org/10.1371/journal. pone.0125766.

[7] A.B. Parekh, J.W. Putney, Store-Operated Calcium Channels, Physiol. Rev. 85 (2005) 757-810, https://doi.org/10.1152/physrev.00057.2003.

[8] Y.-F. Chen, P.-C. Lin, Y.-M. Yeh, L.-H. Chen, M.-R. Shen, Store-Operated Ca2+ Entry in Tumor Progression: From Molecular Mechanisms to Clinical Implications, Cancers 11 (2019) 899, https://doi.org/10.3390/cancers11070899.

[9] G.S. Pitt, M. Matsui, C. Cao, Voltage-Gated Calcium Channels in Nonexcitable Tissues, Annu. Rev. Physiol. 83 (2021) null, https://doi.org/10.1146/annurevphysiol-031620-091043.

[10] P.J. Buchanan, K.D. McCloskey, CaV channels and cancer: canonical functions indicate benefits of repurposed drugs as cancer therapeutics, Eur Biophys $\mathrm{J} 45$ (2016) 621-633, https://doi.org/10.1007/s00249-016-1144-z.

[11] N. Déliot, B. Constantin, Plasma membrane calcium channels in cancer: Alterations and consequences for cell proliferation and migration, Biochim. Biophys. Acta BBA - Biomembr. 1848 (2015) 2512-2522, https://doi.org/10.1016/j. bbamem.2015.06.009.

[12] S. Alinezhad, R.-M. Väänänen, J. Mattsson, Y. Li, T. Tallgrén, N.T. Ochoa, A. Bjartell, M. Åkerfelt, P. Taimen, P.J. Boström, K. Pettersson, M. Nees, Validation of Novel Biomarkers for Prostate Cancer Progression by the Combination of Bioinformatics, Clinical and Functional Studies, PLOS ONE 11 (2016), e0155901, https://doi.org/10.1371/journal.pone.0155901.

[13] M. Scaravilli, S. Koivukoski, L. Latonen, Androgen-Driven Fusion Genes and Chimeric Transcripts in Prostate Cancer, Front. Cell Dev. Biol. 9 (2021), 623809, https://doi.org/10.3389/fcell.2021.623809.

[14] R. Chen, X. Zeng, R. Zhang, J. Huang, X. Kuang, J. Yang, J. Liu, O. Tawfik, J. Brantley Thrasher, B. Li, Cav1.3 channel $\alpha 1 \mathrm{D}$ protein is overexpressed and modulates androgen receptor transactivation in prostate cancers11This work was partially supported by grants from DoD PCRP program (W81XWH-09-1-0455) and KUMC Valk Foundation to Dr Benyi Li, and grants from China Natural Science Foundation to Dr Benyi Li (NSFC \# 81172427) and Dr Jun Yang (NSFC \#81101927). This project was also supported by the "Chutian Scholar" program funded by Hubei Province of China dedicated to China Three Gorges University, Urol. Oncol. Semin. Orig. Investig. 32 (2014) 524-536, https://doi.org/10.1016/j. urolonc.2013.05.011.

[15] Y. Ji, Z. Han, L. Shao, Y. Zhao, Ultrasound-targeted microbubble destruction of calcium channel subunit $\alpha$ 1D siRNA inhibits breast cancer via G protein-coupled receptor 30, Oncol. Rep. 36 (2016) 1886-1892.

[16] J. Hao, X. Bao, B. Jin, X. Wang, Z. Mao, X. Li, L. Wei, D. Shen, J. Wang, Ca2+ channel subunit $\alpha 1 \mathrm{D}$ promotes proliferation and migration of endometrial cancer cells mediated by $17 \beta$-estradiol via the $G$ protein-coupled estrogen receptor, FASEB J (2015), https://doi.org/10.1096/fj.14-265603 fj.14-265603.

[17] A. Zuccotti, S. Clementi, T. Reinbothe, A. Torrente, D.H. Vandael, A. Pirone, Structural and functional differences between L-type calcium channels: crucial issues for future selective targeting, Trends Pharmacol. Sci. 32 (2011) 366-375, https://doi.org/10.1016/j.tips.2011.02.012.

[18] Y. Fourbon, M. Guéguinou, R. Félix, B. Constantin, A. Uguen, G. Fromont, L. Lajoie, C. Magaud, T. Lecomte, E. Chamorey, A. Chatelier, O. Mignen, M. Potier-Cartereau, A. Chantôme, P. Bois, C. Vandier, Ca 2+ protein alpha 1D of CaV1.3 regulates intracellular calcium concentration and migration of colon cancer cells through a non-canonical activity, Sci. Rep. 7 (2017) 14199, https://doi.org/10.1038/s41598017-14230-1.

[19] M. Prakriya, R.S. Lewis, Store-Operated Calcium Channels, Physiol. Rev. 95 (2015) 1383-1436, https://doi.org/10.1152/physrev.00020.2014.

[20] B. Boutin, N. Tajeddine, G. Monaco, J. Molgo, D. Vertommen, M. Rider, J.B. Parys, G. Bultynck, P. Gailly, Endoplasmic reticulum Ca2+ content decrease by PKAdependent hyperphosphorylation of type 1 IP3 receptor contributes to prostate cancer cell resistance to androgen deprivation, Cell Calcium 57 (2015) 312-320, https://doi.org/10.1016/j.ceca.2015.02.004.

[21] H. Nesbitt, N.M. Byrne, S.N. Williams, L. Ming, J. Worthington, R.J. Errington, L. H. Patterson, P.J. Smith, S.R. McKeown, D.J. McKenna, Targeting Hypoxic Prostate Tumors Using the Novel Hypoxia-Activated Prodrug OCT1002 Inhibits Expression of Genes Associated with Malignant Progression, Clin. Cancer Res. 23 (2017) 1797-1808, https://doi.org/10.1158/1078-0432.CCR-16-1361.

[22] M. Nakazawa, C. Paller, N. Kyprianou, Mechanisms of Therapeutic Resistance in Prostate Cancer, Curr. Oncol. Rep. 19 (2017) 13, https://doi.org/10.1007/s11912017-0568-7.

[23] T. Szarvas, A. Csizmarik, T. Fazekas, A. Hüttl, P. Nyirády, B. Hadaschik, V. Grünwald, L. Püllen, Z. Jurányi, Z. Kocsis, S.F. Shariat, S. Sevcenco, A. Maj-Hes, G. Kramer, Comprehensive analysis of serum chromogranin A and neuron-specific enolase levels in localized and castration-resistant prostate cancer, BJU Int 127 (2021) 44-55, https://doi.org/10.1111/bju.15086.

[24] Z. Culig, J. Hoffmann, M. Erdel, I.E. Eder, A. Hobisch, A. Hittmair, G. Bartsch, G. Utermann, M.R. Schneider, K. Parczyk, H. Klocker, Switch from antagonist to agonist of the androgen receptor blocker bicalutamide is associated with prostate tumour progression in a new model system, Br. J. Cancer. 81 (1999) 242-251, https://doi.org/10.1038/sj.bjc.6690684.

[25] B.S. Taylor, N. Schultz, H. Hieronymus, A. Gopalan, Y. Xiao, B.S. Carver, V. K. Arora, P. Kaushik, E. Cerami, B. Reva, Y. Antipin, N. Mitsiades, T. Landers, I. Dolgalev, J.E. Major, M. Wilson, N.D. Socci, A.E. Lash, A. Heguy, J.A. Eastham, H.I. Scher, V.E. Reuter, P.T. Scardino, C. Sander, C.L. Sawyers, W.L. Gerald, Integrative genomic profiling of human prostate cancer, Cancer Cell 18 (2010) 11-22, https://doi.org/10.1016/j.ccr.2010.05.026. 
[26] R.A. Irizarry, B.M. Bolstad, F. Collin, L.M. Cope, B. Hobbs, T.P. Speed, Summaries of Affymetrix GeneChip probe level data, Nucleic Acids Res 31 (2003) e15, https:// doi.org/10.1093/nar/gng015.

[27] M.S. Geybels, J.J. Alumkal, M. Luedeke, A. Rinckleb, S. Zhao, I.M. Shui, M. Bibikova, B. Klotzle, P.A. van den Brandt, E.A. Ostrander, J.-B. Fan, Z. Feng, C. Maier, J.L. Stanford, Epigenomic profiling of prostate cancer identifies differentially methylated genes in TMPRSS2:ERG fusion-positive versus fusionnegative tumors, Clin. Epigenetics. 7 (2015) 128, https://doi.org/10.1186/s13148 015-0161-6.

[28] P. Paulo, F.R. Ribeiro, J. Santos, D. Mesquita, M. Almeida, J.D. Barros-Silva, H. Itkonen, R. Henrique, C. Jerónimo, A. Sveen, I.G. Mills, R.I. Skotheim, R. A. Lothe, M.R. Teixeira, Molecular subtyping of primary prostate cancer reveals specific and shared target genes of different ETS rearrangements, Neoplasia N. Y. N. 14 (2012) 600-611.

[29] S.A. Tomlins, B. Laxman, S. Varambally, X. Cao, J. Yu, B.E. Helgeson, Q. Cao, J. R. Prensner, M.A. Rubin, R.B. Shah, R. Mehra, A.M. Chinnaiyan, Role of the TMPRSS2-ERG Gene Fusion in Prostate Cancer, Neoplasia 10 (2008) 177, https:// doi.org/10.1593/neo.07822. -IN9.

[30] J.L. Boormans, H. Korsten, A.J.C. Ziel-van der Made, G.J.L.H. van Leenders, C.V. de Vos, G. Jenster, J. Trapman, Identification of TDRD1 as a direct target gene of ERG in primary prostate cancer, Int. J. Cancer. 133 (2013) 335-345, https://doi.org/ 10.1002/ijc. 28025.

[31] G. Zhu, Z. Liu, J.I. Epstein, C. Davis, C.S. Christudass, H.B. Carter, P. Landis, H. Zhang, J.-Y. Chung, S.M. Hewitt, M.C. Miller, R.W. Veltri, A Novel Quantitative Multiplex Tissue Immunoblotting for Biomarkers Predicts a Prostate Cancer Aggressive Phenotype, Cancer Epidemiol, Biomark. Prev. Publ. Am. Assoc. Cancer Res. Cosponsored Am. Soc. Prev. Oncol. (2015), https://doi.org/10.1158/10559965.EPI-15-0496.

[32] T. Chandrasekar, J.C. Yang, A.C. Gao, C.P. Evans, Mechanisms of resistance in castration-resistant prostate cancer (CRPC), Transl. Androl. Urol. 4 (2015) 365-380, https://doi.org/10.3978/j.issn.2223-4683.2015.05.02.

[33] X. Wang, Y. Qiao, I.A. Asangani, B. Ateeq, A. Poliakov, M. Cieślik, S. Pitchiaya, B.V. S.K. Chakravarthi, X. Cao, X. Jing, C.X. Wang, I.J. Apel, R. Wang, J.C.-Y. Tien, K. M. Juckette, W. Yan, H. Jiang, S. Wang, S. Varambally, A.M. Chinnaiyan, Development of Peptidomimetic Inhibitors of the ERG Gene Fusion Product in Prostate Cancer, Cancer Cell 31 (2017) 532-548, https://doi.org/10.1016/j. ccell.2017.02.017, e7.

[34] M. Flourakis, V. Lehen'kyi, B. Beck, M. Raphaël, M. Vandenberghe, F.V. Abeele, M. Roudbaraki, G. Lepage, B. Mauroy, C. Romanin, Y. Shuba, R. Skryma, N. Prevarskaya, Orai1 contributes to the establishment of an apoptosis-resistant phenotype in prostate cancer cells, Cell Death Dis 1 (2010) e75, https://doi.org/ 10.1038/cddis.2010.52.

[35] P. Mariot, K. Vanoverberghe, N. Lalevée, M.F. Rossier, N. Prevarskaya, Overexpression of an $\alpha 1 \mathrm{H}$ (Cav3.2) T-type Calcium Channel during Neuroendocrine Differentiation of Human Prostate Cancer Cells, J. Biol. Chem. 277 (2002) 10824-10833, https://doi.org/10.1074/jbc.M108754200.

[36] J.L. Wilding, W.F. Bodmer, Cancer Cell Lines for Drug Discovery and Development, Cancer Res 74 (2014) 2377-2384, https://doi.org/10.1158/0008-5472.CAN-132971.

[37] R.J. Geraghty, A. Capes-Davis, J.M. Davis, J. Downward, R.I. Freshney, I. Knezevic, R. Lovell-Badge, J.R.W. Masters, J. Meredith, G.N. Stacey, P. Thraves, M. Vias, Guidelines for the use of cell lines in biomedical research, Br. J. Cancer. 111 (2014) 1021-1046, https://doi.org/10.1038/bjc.2014.166.

[38] H. Huang, D. Yu, T.W. Soong, C-terminal alternative splicing of CaV1.3 channels distinctively modulates their dihydropyridine sensitivity, Mol. Pharmacol. 84 (2013) 643-653, https://doi.org/10.1124/mol.113.087155.

[39] K. Vanoverberghe, F. Vanden Abeele, P. Mariot, G. Lepage, M. Roudbaraki, J. L. Bonnal, B. Mauroy, Y. Shuba, R. Skryma, N. Prevarskaya, Ca2+ homeostasis and apoptotic resistance of neuroendocrine-differentiated prostate cancer cells, Cell Death Differ 11 (2004) 321-330, https://doi.org/10.1038/sj.cdd.4401375.

[40] R. Skryma, P. Mariot, X.Le Bourhis, F. Van Coppenolle, Y. Shuba, F.V. Abeele, G. Legrand, S. Humez, B. Boilly, N. Prevarskaya, Store depletion and store-operated $\mathrm{Ca} 2+$ current in human prostate cancer LNCaP cells: involvement in apoptosis, J. Physiol. 527 (2000) 71-83, https://doi.org/10.1111/j.1469-7793.2000.00071. $\mathrm{X}$.

[41] A.M. Lopez-Guerrero, C. Pascual-Caro, F.J. Martin-Romero, E. Pozo-Guisado, Storeoperated calcium entry is dispensable for the activation of ERK1/2 pathway in prostate cancer cells, Cell. Signal. 40 (2017) 44-52, https://doi.org/10.1016/j. cellsig.2017.08.010.

[42] C. Dubois, F. Vanden Abeele, V. Lehen'kyi, D. Gkika, B. Guarmit, G. Lepage, C. Slomianny, A.S. Borowiec, G. Bidaux, M. Benahmed, Y. Shuba, N. Prevarskaya Remodeling of Channel-Forming ORAI Proteins Determines an Oncogenic Switch in Prostate Cancer, Cancer Cell 26 (2014) 19-32, https://doi.org/10.1016/j. ccr.2014.04.025.

[43] A. Katzenwadel, P. Wolf, Androgen deprivation of prostate cancer: Leading to a therapeutic dead end, Cancer Lett 367 (2015) 12-17, https://doi.org/10.1016/j. canlet.2015.06.021.

[44] M.J. Sikora, M.D. Johnson, A.V. Lee, S. Oesterreich, Endocrine Response Phenotypes Are Altered by Charcoal-Stripped Serum Variability, Endocrinology 157 (2016) 3760-3766, https://doi.org/10.1210/en.2016-1297.

[45] D.G.A. Burton, M.G. Giribaldi, A. Munoz, K. Halvorsen, A. Patel, M. Jorda, C. Perez-Stable, P. Rai, Androgen Deprivation-Induced Senescence Promotes
Outgrowth of Androgen-Refractory Prostate Cancer Cells, PLoS ONE 8 (2013) e68003, https://doi.org/10.1371/journal.pone.0068003.

[46] B.G. Sánchez, A. Bort, D. Vara-Ciruelos, I. Díaz-Laviada, Androgen Deprivation Induces Reprogramming of Prostate Cancer Cells to Stem-Like Cells, Cells 9 (2020) 1441, https://doi.org/10.3390/cells9061441.

[47] J.M. Kokontis, N. Hay, S. Liao, Progression of LNCaP Prostate Tumor Cells during Androgen Deprivation: Hormone-Independent Growth, Repression of Proliferation by Androgen, and Role for p27Kip1 in Androgen-Induced Cell Cycle Arrest, Mol. Endocrinol. 12 (1998) 941-953, https://doi.org/10.1210/mend.12.7.0136.

[48] S. Kim, H.-M. Yun, J.-H. Baik, K.C. Chung, S.-Y. Nah, H. Rhim, Functional interaction of neuronal Cav1.3 L-type calcium channel with ryanodine receptor type 2 in the rat hippocampus, J. Biol. Chem. 282 (2007) 32877-32889, https:// doi.org/10.1074/jbc.M701418200.

[49] A.G. Torrente, P. Mesirca, P. Neco, R. Rizzetto, S. Dubel, C. Barrere, M. SineggerBrauns, J. Striessnig, S. Richard, J. Nargeot, A.M. Gomez, M.E. Mangoni, L-type Cav1.3 channels regulate ryanodine receptor-dependent $\mathrm{Ca} 2+$ release during sinoatrial node pacemaker activity, Cardiovasc. Res. 109 (2016) 451-461, https://doi. org/10.1093/cvr/cvw006.

[50] J.M. Power, P. Sah, Intracellular calcium store filling by an L-type calcium current in the basolateral amygdala at subthreshold membrane potentials, J. Physiol. 562 (2005) 439-453, https://doi.org/10.1113/jphysiol.2004.076711.

[51] J.D. Debes, R.O. Roberts, D.J. Jacobson, C.J. Girman, M.M. Lieber, D.J. Tindall, S. J. Jacobsen, Inverse association between prostate cancer and the use of calcium channel blockers, Cancer Epidemiol. Biomarkers Prev. 13 (2004) 255-259.

[52] Y. Fan, Y. Zhou, D. Gong, C. Zou, No evidence for increased prostate cancer risk among calcium channel blockers user, Int. J. Cardiol. 201 (2015) 255-257, https:// doi.org/10.1016/j.ijcard.2015.08.046.

[53] K.R. Loughlin, Calcium channel blockers and prostate cancer, Urol. Oncol. Semin. Orig. Investig. 32 (2014) 537-538, https://doi.org/10.1016/j. urolonc.2013.08.001.

[54] A.L. Fitzpatrick, J.R. Daling, C.D. Furberg, R.A. Kronmal, J.L. Weissfeld, Heart Rate Hypertension, Use of Antihypertensives, and Incident Prostate Cancer, Ann. Epidemiol. 11 (2001) 534-542, https://doi.org/10.1016/S1047-2797(01)00246-0.

[55] J.P. Bannister, M.D. Leo, D. Narayanan, W. Jangsangthong, A. Nair, K.W. Evanson, J. Pachuau, K.S. Gabrick, F.A. Boop, J.H. Jaggar, The voltage-dependent L-type $\mathrm{Ca} 2+(\mathrm{CaV} 1.2)$ channel C-terminus fragment is a bi-modal vasodilator, J. Physiol. 591 (2013) 2987-2998, https://doi.org/10.1113/jphysiol.2013.251926.

[56] L. Lu, P. Sirish, Z. Zhang, R.L. Woltz, N. Li, V. Timofeyev, A.A. Knowlton, X.D. Zhang, E.N. Yamoah, N. Chiamvimonvat, Regulation of Gene Transcription by Voltage-Gated L-Type Calcium Channel, Cav1.3, J. Biol. Chem. (2014), https://doi. org/10.1074/jbc.M114.586883 jbc.M114.586883.

[57] N. Gomez-Ospina, F. Tsuruta, O. Barreto-Chang, L. Hu, R. Dolmetsch, The C Terminus of the L-Type Voltage-Gated Calcium Channel CaV1.2 Encodes a Transcription Factor, Cell 127 (2006) 591-606, https://doi.org/10.1016/j. cell.2006.10.017.

[58] T.-O. Dondoo, T. Fukumori, K. Daizumoto, T. Fukawa, M. Kohzuki, M. Kowada, Y. Kusuhara, H. Mori, H. Nakatsuji, M. Takahashi, H.-O. Kanayama, Galectin-3 Is Implicated in Tumor Progression and Resistance to Anti-androgen Drug Through Regulation of Androgen Receptor Signaling in Prostate Cancer, Anticancer Res 37 (2017) 125-134, https://doi.org/10.21873/anticanres.11297.

[59] K. Langenbach, ATCC technology assessment of Roche xCELLigence System: an electronic impedance-based cell sensing unit, BioTechniques 49 (2010) 905-906, https://doi.org/10.2144/000113575.

[60] S.B. Williams, A.H. Lay, C.S. Lau, D.Y. Josephson, T.G. Wilson, T.K. Choueiri, S. K. Pal, New therapies for castrate-resistant prostate cancer, Expert Opin. Pharmacother. 12 (2011) 2069-2074, https://doi.org/10.1517/ 14656566.2011.590133.

[61] A. Hobisch, A. Fritzer, B. Comuzzi, M. Fiechtl, K. Malinowska, H. Steiner, G. Bartsch, Z. Culig, The androgen receptor pathway is by-passed in prostate cancer cells generated after prolonged treatment with bicalutamide, The Prostate 66 (2006) 413-420, https://doi.org/10.1002/pros.20365.

[62] P. Yu, X. Duan, Y. Cheng, C. Liu, Y. Chen, W. Liu, B. Yin, X. Wang, Z. Tao, Androgen-independent LNCaP cells are a subline of LNCaP cells with a more aggressive phenotype and androgen suppresses their growth by inducing cell cycle arrest at the G1 phase, Int. J. Mol. Med. 40 (2017) 1426-1434, https://doi.org/ 10.3892/ijmm.2017.3125.

[63] D.T. Hoang, K.A. Iczkowski, D. Kilari, W. See, M.T. Nevalainen, Androgen receptordependent and -independent mechanisms driving prostate cancer progression: Opportunities for therapeutic targeting from multiple angles, Oncotarget 8 (2017) 3724-3745, https://doi.org/10.18632/oncotarget.12554.

[64] J.A. Ardura, L. Álvarez-Carrión, I. Gutiérrez-Rojas, V. Alonso, Role of Calcium Signaling in Prostate Cancer Progression: Effects on Cancer Hallmarks and Bone Metastatic Mechanisms, Cancers (2020) 12, https://doi.org/10.3390/ cancers12051071.

[65] M. Flourakis, N. Prevarskaya, Insights into Ca2+ homeostasis of advanced prostate cancer cells, Biochim. Biophys. Acta BBA - Mol. Cell Res. 1793 (2009) 1105-1109, https://doi.org/10.1016/j.bbamcr.2009.01.009.

[66] K. Vanoverberghe, F. Vanden Abeele, P. Mariot, G. Lepage, M. Roudbaraki, J. L. Bonnal, B. Mauroy, Y. Shuba, R. Skryma, N. Prevarskaya, Ca 2+ homeostasis and apoptotic resistance of neuroendocrine-differentiated prostate cancer cells, Cell Death Differ 11 (2004) 321-330, https://doi.org/10.1038/sj.cdd.4401375. 